\title{
Brownness of Organic Aerosol over the United States: Evidence for Seasonal Biomass Burning and Photobleaching Effects
}

Lung-Wen Antony Chen ${ }^{\mathrm{a}, \mathrm{b}^{*}}$, Judith C. Chow ${ }^{\mathrm{b}, \mathrm{c}}$, Xiaoliang Wang ${ }^{\mathrm{b}}$, Junji Cao ${ }^{\mathrm{c} \dagger}$, Jingqiu Mao ${ }^{\mathrm{d}}$, and John G. Watson ${ }^{\text {b,c }}$

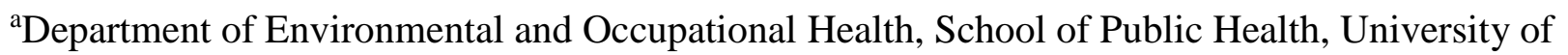
Nevada, Las Vegas, NV, 89154, USA

${ }^{\mathrm{b}}$ Division of Atmospheric Sciences, Desert Research Institute, Reno, NV, 89512, USA

'Institute of Earth Environment, Chinese Academy of Sciences, Xi'an, 710061, China

${ }^{\mathrm{d}}$ Department of Chemistry and Biochemistry, University of Alaska, Fairbanks, AK, 99775, USA

*Corresponding author: Lung-Wen Antony Chen (antony.chen@unlv.edu)

${ }^{\dagger}$ Currently with Institute of Atmospheric Physics, Chinese Academy of Sciences, Beijing, 100029, China

\section{Included in the Supporting Information:}

Page 1-7

Figure S1-S2

Table S1-S2

Text: Hybrid Environmental Receptor Model (HERM) Formulations and Spectral Mass Balance 


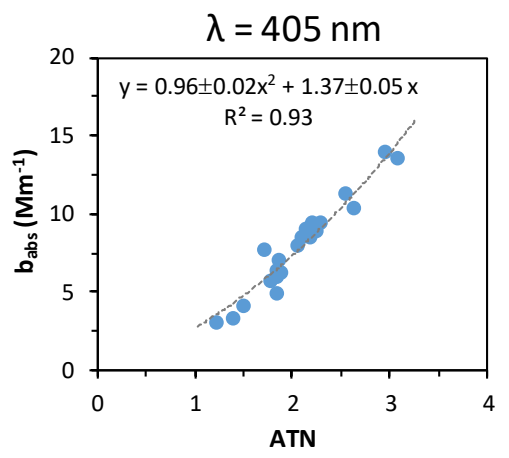

a)

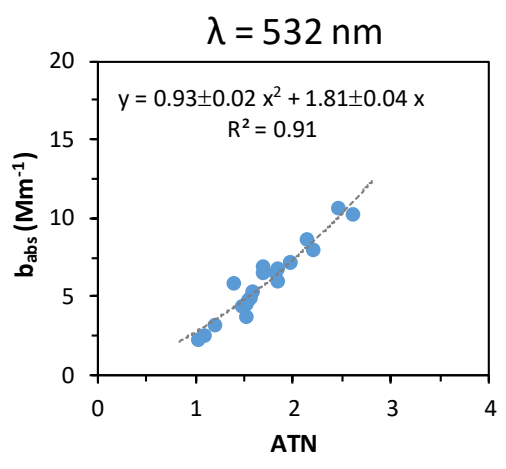

c)

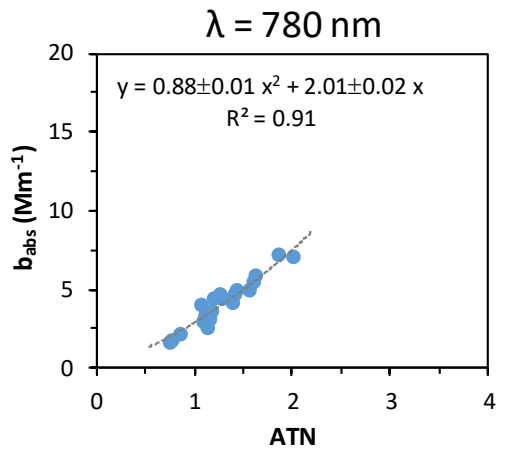

e)

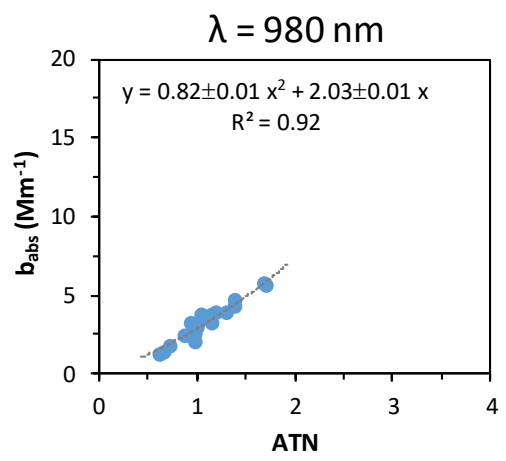

b)

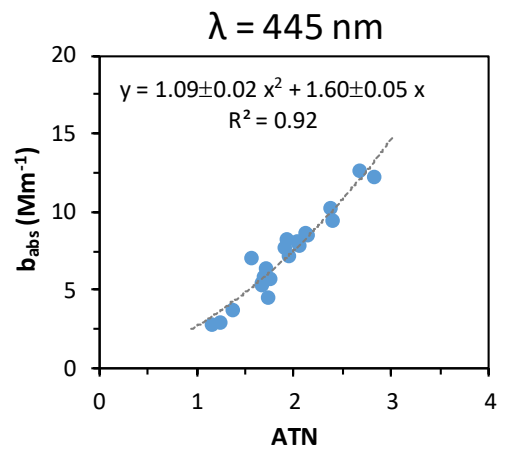

d)
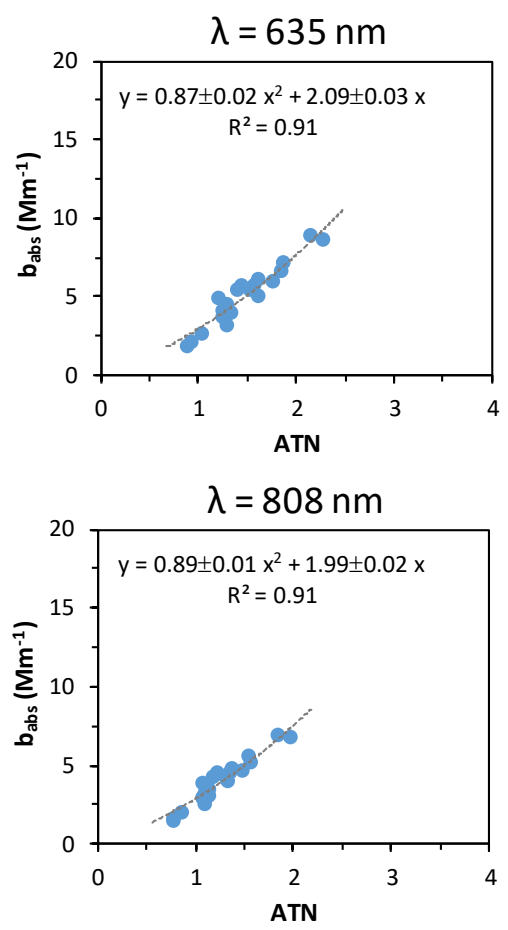

\section{g)}

Figure S1. Conversion curves between the attenuation (ATN) measured by multi-wavelength carbon analyzer and absorption coefficient $\left(b_{a b s}\right)$ of aerosol deposited on filters at seven wavelengths. The curves are robust regressions based on $21 \mathrm{EC}$-dominated samples (EC/TC > 0.5) where $b_{a b s}$ are estimated from the EC concentrations, a mass absorption efficiency (MAE) of $7.4 \mathrm{~m}^{2} \mathrm{gC}^{-1}$ at $635 \mathrm{~nm}$ and a bulk absorption Angström exponent (AAE) of 1 . 


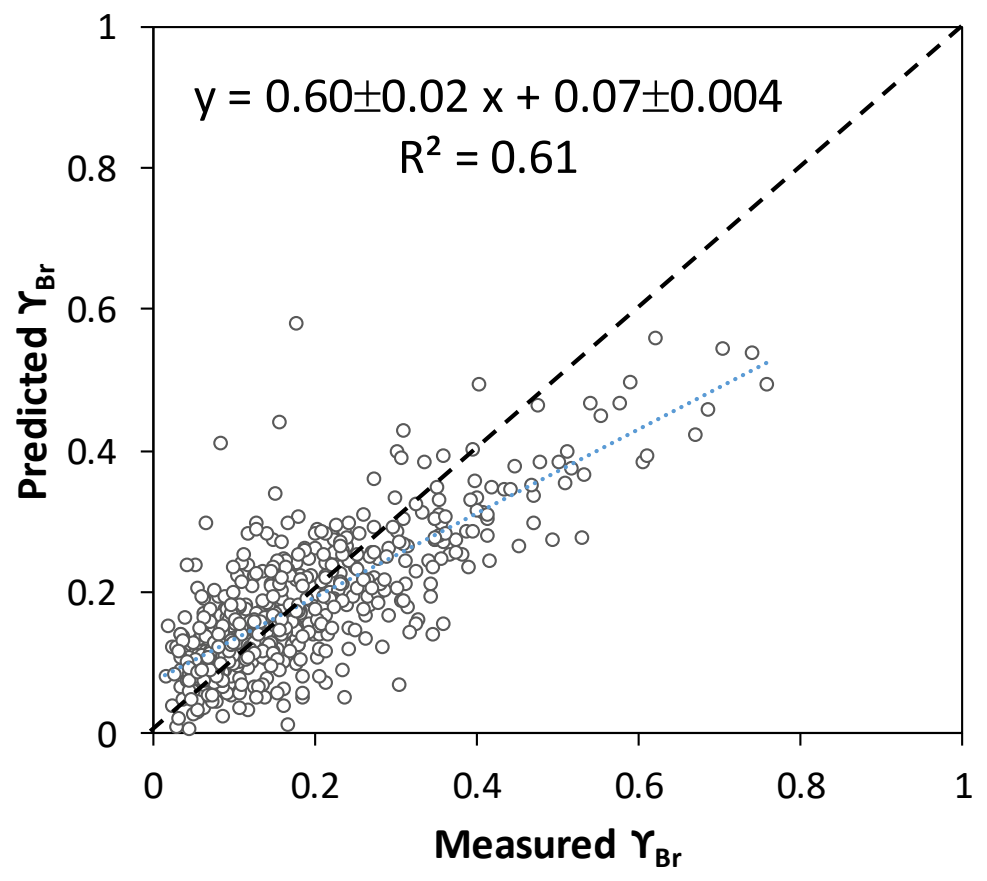

Figure S2. Predicted versus measured seasonal average brownness indices $\left(\Upsilon_{\mathrm{Br}}\right)$ across the IMPROVE network in 2016. Predicted $\Upsilon_{\mathrm{Br}}$ are based on ambient black carbon concentrations and temperatures according to Eq. (5). 
Table S1. Number of IMPROVE samples and effective-variance chemical mass balance (EV$\mathrm{CMB}$ ) performance measures ${ }^{*}$ by filter loading range according to the bulk aerosol light absorption ( $b_{a b s}$ ) averaged over seven wavelengths. $\chi_{k}^{2}$ are sample-specific scaled fitting residues, with $\chi_{k}^{2}<0.5$ indicating a good fit.

\begin{tabular}{|l|r|r|r|r|r|r|}
\hline $\begin{array}{l}\text { Average } b_{\mathrm{abs}} \\
\left(\mathrm{Mm}^{-1}\right)\end{array}$ & \# of Samples & $\begin{array}{c}0 \leq \chi_{k}^{2}<0.5 \\
(\%)\end{array}$ & $\begin{array}{c}0.5 \leq \chi_{k}^{2}<1 \\
(\%)\end{array}$ & $\begin{array}{c}1 \leq \chi_{k}^{2}<2 \\
(\%)\end{array}$ & $\begin{array}{c}2 \leq \chi_{k}^{2}<4 \\
(\%)\end{array}$ & $\begin{array}{c}4 \leq \chi_{k}^{2} \\
(\%)\end{array}$ \\
\hline $\mathbf{0 - \mathbf { 0 . 1 }}$ & 1213 & $99.9 \%$ & $0.1 \%$ & $0.0 \%$ & $0.0 \%$ & $0.0 \%$ \\
\hline $\mathbf{0 . 1 - 1}$ & 11564 & $98.7 \%$ & $0.8 \%$ & $0.3 \%$ & $0.2 \%$ & $0.1 \%$ \\
\hline $\mathbf{1 - 1 0}$ & 5066 & $98.0 \%$ & $0.7 \%$ & $0.2 \%$ & $0.5 \%$ & $0.7 \%$ \\
\hline $\mathbf{1 0 - 1 0 0}$ & 201 & $94.5 \%$ & $3.5 \%$ & $0.0 \%$ & $0.0 \%$ & $2.0 \%$ \\
\hline All & 18044 & $98.5 \%$ & $0.8 \%$ & $0.3 \%$ & $0.2 \%$ & $0.2 \%$ \\
\hline
\end{tabular}

"EV-CMB was performed by the hybrid environmental receptor model (HERM) to apportion carbon into $\mathrm{BC}, \mathrm{BrC}$, and $\mathrm{WtC}$ based on their spectral absorption profiles developed in this study. HERM formulations and performance measures are described further in this Supporting Information. 
Table S2. IMPROVE carbon fractions (TC, EC, BC, and $\mathrm{OC}^{*}$ in $\mu \mathrm{g} \mathrm{m}^{-3}$ ), organic brownness index $\left(\gamma_{\mathrm{Br}}\right)$, and light absorption $\left(\mathrm{b}_{\mathrm{abs}}\right.$ in $\left.\mathrm{Mm}^{-1}\right)$ by site type and season in 2016. Averages \pm standard deviations and standard errors (in bracket) are based on site-specific means (annual or seasonal) across 158 sites, excluding two IMPROVE sites in Virgin Islands and South Korea.

\begin{tabular}{|c|c|c|c|c|c|c|c|c|c|c|}
\hline Site Type & Season & TC & EC & BC & $O C^{*}$ & $\gamma_{\mathrm{Br}}$ & $\begin{array}{l}\text { babs,BC } \\
(405 \mathrm{~nm})\end{array}$ & $\begin{array}{c}\text { babs,OC* } \\
(405 \mathrm{~nm})\end{array}$ & $\begin{array}{l}\text { babs,BC } \\
(532 \mathrm{~nm})\end{array}$ & $\begin{array}{c}\text { babs, } \text { OC }^{*} \\
(532 \mathrm{~nm})\end{array}$ \\
\hline \multirow[t]{10}{*}{ Rural } & Annual & $1.05 \pm 0.96$ & $0.09 \pm 0.07$ & $0.08 \pm 0.05$ & $0.97 \pm 0.93$ & $0.17 \pm 0.08$ & $0.99 \pm 0.65$ & $0.5 \pm 0.42$ & $0.76 \pm 0.49$ & $0.13 \pm 0.11$ \\
\hline & & $(0.08)$ & $(0.01)$ & $(0.004)$ & $(0.08)$ & $(0.01)$ & $(0.05)$ & $(0.03)$ & $(0.04)$ & $(0.01)$ \\
\hline & Winter & $0.65 \pm 0.49$ & $0.09 \pm 0.1$ & $0.08 \pm 0.08$ & $0.57 \pm 0.43$ & $0.27 \pm 0.15$ & $0.96 \pm 0.91$ & $0.61 \pm 0.74$ & $0.73 \pm 0.69$ & $0.16 \pm 0.2$ \\
\hline & & $(0.04)$ & $(0.01)$ & $(0.01)$ & $(0.03)$ & $(0.01)$ & $(0.07)$ & $(0.06)$ & $(0.06)$ & $(0.02)$ \\
\hline & Spring & $1.2 \pm 3.47$ & $0.09 \pm 0.1$ & $0.08 \pm 0.07$ & $1.12 \pm 3.43$ & $0.16 \pm 0.09$ & $0.94 \pm 0.79$ & $0.47 \pm 0.62$ & $0.72 \pm 0.6$ & $0.13 \pm 0.17$ \\
\hline & & $(0.29)$ & $(0.01)$ & $(0.01)$ & $(0.28)$ & $(0.01)$ & $(0.06)$ & $(0.05)$ & $(0.05)$ & $(0.01)$ \\
\hline & Summer & $1.32 \pm 0.78$ & $0.09 \pm 0.08$ & $0.09 \pm 0.05$ & $1.23 \pm 0.74$ & $0.08 \pm 0.04$ & $1.02 \pm 0.62$ & $0.32 \pm 0.32$ & $0.78 \pm 0.47$ & $0.09 \pm 0.09$ \\
\hline & & $(0.06)$ & $(0.01)$ & (0.004) & $(0.06)$ & (0.003) & $(0.05)$ & $(0.03)$ & $(0.04)$ & $(0.01)$ \\
\hline & Fall & $1.04 \pm 0.65$ & $0.1 \pm 0.08$ & $0.09 \pm 0.06$ & $0.95 \pm 0.61$ & $0.17 \pm 0.08$ & $1.03 \pm 0.76$ & $0.57 \pm 0.52$ & $0.79 \pm 0.58$ & $0.15 \pm 0.14$ \\
\hline & & $(0.05)$ & $(0.01)$ & $(0.01)$ & $(0.05)$ & $(0.01)$ & $(0.06)$ & $(0.04)$ & $(0.05)$ & $(0.01)$ \\
\hline \multirow[t]{10}{*}{ Urban } & Annual & $2.69 \pm 0.55$ & $0.57 \pm 0.11$ & $0.62 \pm 0.12$ & $2.08 \pm 0.49$ & $0.30 \pm 0.07$ & $7.35 \pm 1.39$ & $2.03 \pm 0.59$ & $5.59 \pm 1.06$ & $0.55 \pm 0.16$ \\
\hline & & $(0.18)$ & $(0.04)$ & $(0.04)$ & $(0.16)$ & $(0.02)$ & $(0.46)$ & $(0.20)$ & $(0.35)$ & $(0.05)$ \\
\hline & Winter & $3.64 \pm 1.94$ & $0.81 \pm 0.41$ & $0.87 \pm 0.46$ & $2.78 \pm 1.52$ & $0.48 \pm 0.15$ & $10.4 \pm 5.44$ & $3.87 \pm 1.98$ & $7.89 \pm 4.14$ & $1.04 \pm 0.53$ \\
\hline & & $(0.65)$ & $(0.14)$ & $(0.15)$ & $(0.51)$ & $(0.05)$ & $(1.81)$ & $(0.66)$ & (1.38) & $(0.18)$ \\
\hline & Spring & $2.09 \pm 0.49$ & $0.43 \pm 0.14$ & $0.46 \pm 0.13$ & $1.63 \pm 0.41$ & $0.24 \pm 0.08$ & $5.45 \pm 1.61$ & $1.21 \pm 0.38$ & $4.15 \pm 1.23$ & $0.33 \pm 0.1$ \\
\hline & & $(0.16)$ & $(0.05)$ & $(0.04)$ & $(0.14)$ & $(0.03)$ & $(0.54)$ & $(0.13)$ & $(0.41)$ & $(0.03)$ \\
\hline & Summer & $2.06 \pm 0.65$ & $0.38 \pm 0.17$ & $0.41 \pm 0.16$ & $1.65 \pm 0.54$ & $0.12 \pm 0.06$ & $4.95 \pm 1.86$ & $0.65 \pm 0.36$ & $3.77 \pm 1.42$ & $0.17 \pm 0.1$ \\
\hline & & $(0.22)$ & $(0.06)$ & $(0.05)$ & $(0.18)$ & $(0.02)$ & $(0.62)$ & $(0.12)$ & $(0.47)$ & $(0.03)$ \\
\hline & Fall & $2.97 \pm 0.75$ & $0.66 \pm 0.18$ & $0.72 \pm 0.16$ & $2.25 \pm 0.68$ & $0.35 \pm 0.08$ & $8.63 \pm 1.93$ & $2.39 \pm 0.54$ & $6.57 \pm 1.47$ & $0.65 \pm 0.15$ \\
\hline & & $(0.25)$ & $(0.06)$ & $(0.05)$ & $(0.23)$ & $(0.03)$ & $(0.64)$ & $(0.18)$ & $(0.49)$ & $(0.05)$ \\
\hline \multirow[t]{2}{*}{ All Sites } & Annual & $1.14 \pm 1.01$ & $0.12 \pm 0.13$ & $0.11 \pm 0.14$ & $1.03 \pm 0.95$ & $0.18 \pm 0.09$ & $1.36 \pm 1.64$ & $0.58 \pm 0.56$ & $1.03 \pm 1.25$ & $0.16 \pm 0.15$ \\
\hline & & $(0.08)$ & $(0.01)$ & $(0.01)$ & $(0.08)$ & $(0.01)$ & $(0.13)$ & $(0.04)$ & $(0.10)$ & $(0.01)$ \\
\hline
\end{tabular}




\section{Hybrid Environmental Receptor Model (HERM) Formulations and Spectral Mass Balance}

HERM $^{1}$ seeks to solve the chemical mass balance model:

$$
C_{i k}=\sum_{j=1}^{J} F_{i j} S_{j k}
$$

where $C_{i k}$ is the measured carbon concentration or light absorption (indexed by $i$ ) for sample $k, J$ indicates the number of sources that impact the sample with the source profiles $F_{i j}$, and the source contribution $S_{j k}$ can be solved by minimizing

$$
\chi^{2}=\frac{1}{K(I-J)-\sum_{i=1}^{I} \sum_{j=1}^{J} \delta_{i j}} \sum_{k=1}^{K} \sum_{i=1}^{I} \frac{\left(C_{i k}-\sum_{j=1}^{J} F_{i j} S_{j k}\right)^{2}}{E V_{i k}}
$$

where $F_{i j}$ can be known or unknown. The leading term in Eq. (S2) is the degree of freedom in the model depending on the number of samples $(K)$, species $(I)$, sources $(J)$, and unknowns in $F_{i j}$, i.e., $\delta_{i j}=0$ if source profile element $F_{i j}$ is measured and $\delta_{i j}=1$ when $F_{i j}$ is unknown or missing. $E V_{i k}$ is the effective variance consisting of uncertainties $\sigma_{C_{i k}}$ and $\sigma_{F_{i j}}$ in measured $C_{i k}$ and $F_{i j}$, respectively:

$$
E V_{i k}=\sigma_{C_{i k}}^{2}+\sum_{j=1}^{J}\left(\sigma_{F_{i j}}^{2} S_{j k}^{2}+\delta_{i j} \sigma_{C_{i k}}^{2}\right)
$$

Note HERM formulation is reduced to the effective variance chemical mass balance model (EVCMB, see Watson et al. $^{2}$ ) when all $F_{i j}$ are specified, thus all $\delta_{i j}=0$.

The HERM software calls the Multilinear Engine ${ }^{3}$ to solve Eq. (S2) for $S_{j k}$ and every unknown $F_{i j}$. Uncertainty (i.e., standard deviation $\sigma_{S_{j k}}$ ) of source contribution $S_{j k}$ is then calculated by:

$$
\sigma_{S j k}^{2}=\left(F^{\prime}\left(d E V_{k}\right)^{-1} F\right)_{j j}^{-1} \times \chi_{k}^{2}
$$

where $d E V_{k}$ is an $I \times I$ diagonal matrix with diagonal elements $\left(d E V_{k}\right)_{i i}=E V_{i k}$ and $\chi_{k}^{2}$ is the samplespecific residue that indicates the goodness of fit for the sample:

$$
\chi_{k}^{2}=\frac{K}{K(I-J)-\sum_{i=1}^{I} \sum_{j=1}^{J} \delta_{i j}} \sum_{i=1}^{I} \frac{\left(C_{i k}-\sum_{j=1}^{J} F_{i j} S_{j k}\right)^{2}}{E V_{i k}}
$$

A good fit should have $\chi_{k}^{2}<0.5$ so that the deviation between measured and fitted $C_{i k}$ is less than half the effective variance. In addition, species-specific residues, $\chi_{i}^{2}$, are calculated as: 


$$
\chi_{i}^{2}=\frac{I}{K(I-J)-\sum_{i=1}^{I} \sum_{j=1}^{J} \delta_{i j}} \sum_{k=1}^{K} \frac{\left(C_{i k}-\sum_{j=1}^{J} F_{i j} S_{j k}\right)^{2}}{E V_{i k}}
$$

In this study, ambient measurements and source profiles consist of carbon mass concentration and light absorption at seven wavelengths. The first (screening) stage of HERM modeling used the black carbon $(\mathrm{BC})$ and white carbon $(\mathrm{WtC})$ source profiles while leaving the brown carbon $(\mathrm{BrC})$ profile as unknown. The model output of $\mathrm{BrC}$ and $\mathrm{WtC}$ contributions are combined to determine $\mathrm{OC}^{*}$ and $\mathrm{b}_{\mathrm{abs}}{ }^{*}$ (i.e., non-BC organic carbon and light absorption), as shown in Figure 1. The twenty samples identified from the upper edge of distribution in Figure 1 formed the BrC profile, which entered the second stage of modeling. The second stage of HERM modeling used the BC, $\mathrm{BrC}$, and $\mathrm{WtC}$ profiles (Figure 2) with the $\mathrm{EV}-\mathrm{CMB}$ mode to calculate the carbon apportionment $\left(S_{j k}\right)$ and uncertainty $\left(\sigma_{S_{j k}}\right)$. All source contributions and uncertainties are documented in the provided supplementary dataset.

\section{References}

1. Chen, L.-W.A. and Cao, J., 2018. PM2.5 source apportionment using a hybrid environmental receptor model. Environmental Science \& Technology, 52(11), pp.6357-6369.

2. Watson, J.G., Cooper, J.A. and Huntzicker, J.J., 1984. The effective variance weighting for least squares calculations applied to the mass balance receptor model. Atmospheric Environment (1967), 18(7), pp.1347-1355.

3. Paatero, P., 1999. The multilinear engine - a table-driven, least squares program for solving multilinear problems, including the n-way parallel factor analysis model. Journal of Computational and Graphical Statistics, 8(4), pp.854-888. 